\title{
Design and Development of Instant Power Supply
}

\author{
Ashraf Mehbub ${ }^{1}$, Humayun Kabir ${ }^{2 *}$, Jahirul Islam Khandaker ${ }^{3}$, Md. Abdul \\ Mannan Chowdhury ${ }^{4}$ \\ ${ }^{1,2,3,4}$ Department of Physics, Jahangirnagar University, Savar, Dhaka-1342.
}

\begin{abstract}
Instant Power Supply unit (IPS) is an electrical device that provides power when the main supply fails to operate. In the present work an attempt has been made to design and develop an instant power supply unit at the electronics laboratory of department of Physics, Jahangirnagar University. In the present circuit active and passive devices, such as diodes, transistors, capacitors, resistors etc have been used. Two transformers (One Step up and one step down) have also been used in this work. A voltage regulator (LM 338K) is used in the charger circuit so that the battery will be charged properly and will not be over charged. As a result the battery will get long life. Also the output of the device will be automatically stable. A relay circuit has been incorporated so that when the main supply is present the battery will automatically be charged and not provide any output. The main supply would come to the output of the IPS through the relay circuit. The designed circuit is operated successfully and the results obtained are satisfactory.
\end{abstract}

\section{Introduction}

IPS stands for "Instant Power Supply". It is an electrical device that can provide electricity when the main supply is not available. IPS is the ideal solution for continuous power supply facilities during mains failure. A general IPS consists of a charger circuit, a battery, an oscillator circuit and an output circuit. The charger circuit charges the battery properly by using the main supply when it is ON. When the main supply is not available then the battery supplies the power.

The system has many distinct features over the conventional generators. It is fully automatic. It does not require any fuel as like a generator needs. It also does not produce any sound pollution like a generator does. It is the precession IPS designed according to our power line Condition.

The IPS those are available in the market has some limitations such as

- Unstable or unregulated output voltage

- Battery longibility is small

- High cost

To overcome above shortcomings an initiative was taken to design such an IPS that will give a stable output and its battery will serve for a long time compared to the conventional IPS. It will also be available at comparatively low cost [1].

Table 1 The specification of the designed IPS

\begin{tabular}{|c|c|c|}
\hline Serial number & Features & Specifications \\
\hline 1 & Main voltage & $220 \mathrm{~V}, 50 \mathrm{~Hz}$ \\
\hline 2 & $\begin{array}{c}\text { Low voltage power } \\
\text { supply }\end{array}$ & $12 \mathrm{~V} \mathrm{DC}$ \\
\hline 3 & $\begin{array}{c}\text { Temperature range } \\
\text { Output range }\end{array}$ & ${ }^{\circ} \mathrm{C}-30^{\circ} \mathrm{C}$ \\
\hline 4 & Voltage regulator & LM 338K \\
\hline 5 & Power & 120 watt \\
\hline 6 & Back up time & Battery dependent \\
\hline 7 & Use & Two tube lights \\
\hline 8 & &
\end{tabular}




\section{Principle of Operation}

The simplified block diagram of designed IPS is shown in Fig. 1. The 220V AC supply is applied to the input (step down) transformer.15-20V AC from input transformer is then enters in to the rectifier bridge which converts this AC into DC. This $15-20 \mathrm{~V}$ DC is used to charge a $12 \mathrm{~V}$ DC battery through the charger circuit. $12 \mathrm{~V}$ DC is supplied to the oscillator circuit that converts it into $12 \mathrm{~V}$ AC. This $12 \mathrm{~V}$ AC is then amplified and transmitted to the output (step up) transformer. 220V AC supply is achieved from the output transformer.

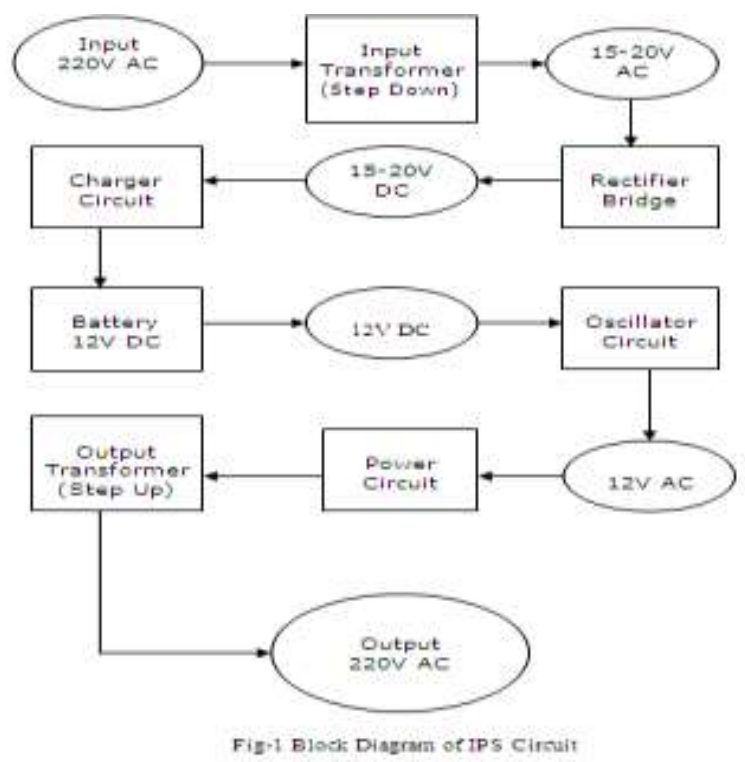

III. Design and Circuit Description

The complete circuit diagram of the designed IPS is shown in Fig. 2. The descriptions of each part are furnished below:

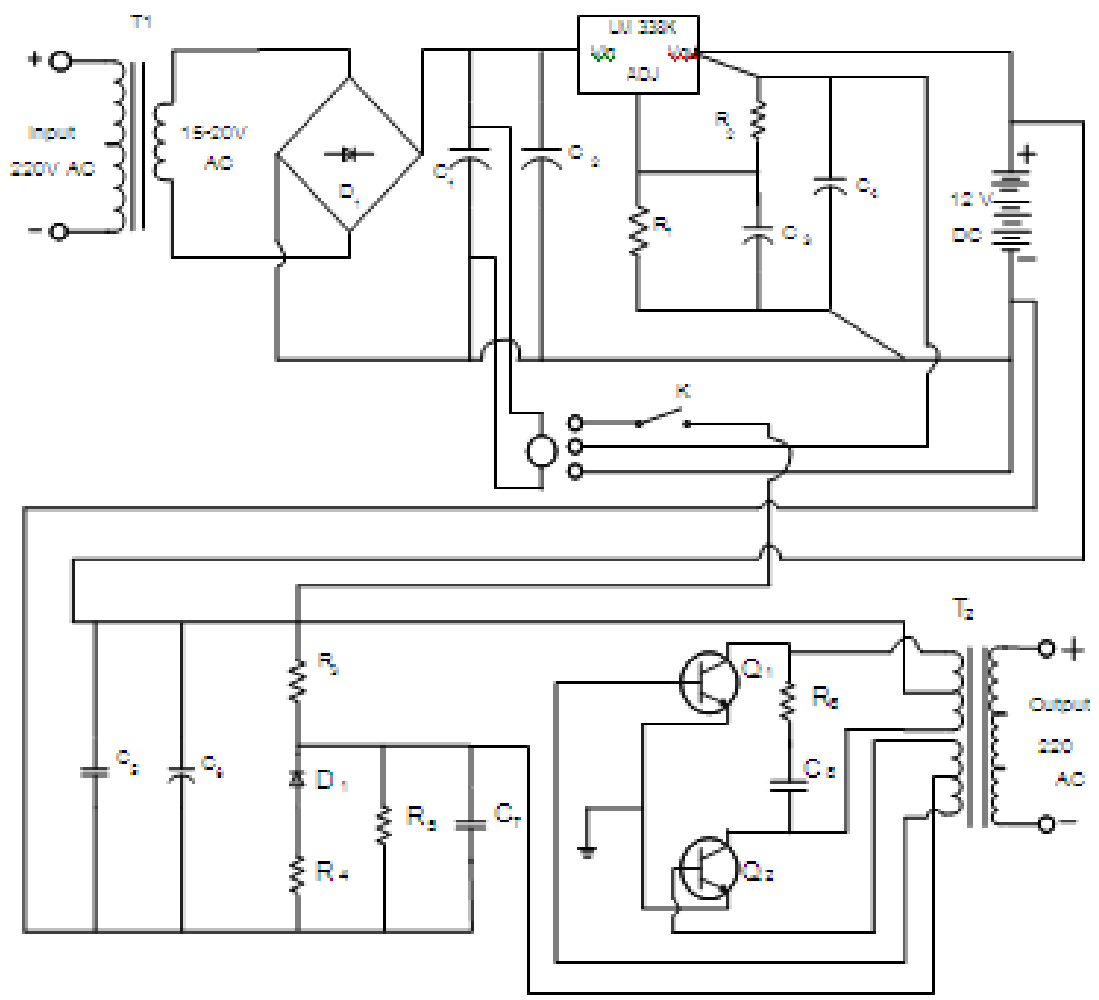

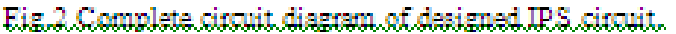

\subsection{V AC Input Supply}

It is the main power supply from the supply line. The main supply of our country is $220 \mathrm{~V}, 50 \mathrm{~Hz}$. 


\subsection{The Input Transformer}

A transformer is an electronic device that transfers electrical energy from one circuit to another through inductively coupled conductors known as the transformer's coils. A transformer has a primary coil and a secondary coil. It transfers or induces AC electrical power from its primary winding to its secondary winding [2]. The transformer used in the designed circuit is a step down transformer. It input is $220 \mathrm{~V}$ but the output is $15-20 \mathrm{~V}$.

\subsection{The Charger Circuit}

The electronic circuit used to chare up a battery or electrical cell is called the charger circuit. Here we have used a charger circuit to charge a 12V DC battery. Charger circuit consists of a diode rectifier D1 filtering capacitors $\mathrm{C} 1, \mathrm{C} 2$, the adjustable voltage regulator LM 338K, resistors R1, R2, capacitors C3, C4 and a relay. $15 \mathrm{~V} \mathrm{AC}$ is rectified and turned into $15 \mathrm{~V}$ pulsating DC by the rectifier D1. This pulsating DC is then converted into pure DC by the filtering capacitors $\mathrm{C} 1$ and $\mathrm{C} 2.15 \mathrm{~V}$ pure $\mathrm{DC}$ is applied to the input of the adjustable voltage regulator LM 338K. Resistors R1 and R2 are used to bias the voltage regulator to a fixed output voltage. The regulator provides an output of about $13.5 \mathrm{~V}$. This $13.5 \mathrm{~V}$ DC is used to charge up a $12 \mathrm{~V}$ DC battery.

\subsection{Battery}

An electrical battery is a combination of one or more electrochemical cells that convert stored chemical energy into electrical energy. Batteries have become a common power source for many household, educational and industrial applications. Batteries come in many sizes; from miniature cells used to power hearing aids and wristwatches to battery banks the size of rooms that provide standby power for telephone exchanges and computer data centers [3].

\subsection{Oscillator Circuit}

Generally, an electronic circuit that produces a repetitive electronic signal is known as an electronic oscillator [4]. More precisely, an oscillator is a circuit that generates a repetitive wave form of fixed amplitude and frequency without any external input signal. Basically the function of an oscillator is to generate alternating current or voltage wave form [5]. Generally Oscillators are characterized by the frequency of their output signal. An audio oscillator produces frequencies in the audio range, about $16 \mathrm{~Hz}$ to $20 \mathrm{kHz}$. An RF oscillator produces signals in the radio frequency (RF) range of about $100 \mathrm{kHz}$ to $100 \mathrm{GHz}$. A low-frequency oscillator (LFO) is an electronic oscillator that generates a frequency below $\approx 20 \mathrm{~Hz}$. Oscillators that produce a high-power AC output from a DC supply are usually termed as inverters.

\section{Basic Constituents of an Oscillator:}

An oscillator contains the following constituents-

- Basic amplifier

- Frequency selecting network

- Positive feedback or negative resistance effect

- Automatic amplitude limiting device [6].

\subsection{The Power Circuit}

A type of circuit that carries power to electrical loads is called the power circuit. In other words the part of an electronic circuit that controls the output of the circuit is known as the power circuit. [7]. A power circuit is generally a proper combination of incoming main power, few transistors and output transformer. It often carries high voltages to the load. In the designed circuit a power push-pull amplifier is used consists of transistors Q1 and Q2.

\subsection{The Output Transformer} $220 \mathrm{~V}$ AC.

It is a step up transformer. Its input is according to the output voltage of the battery and the output is

\section{Results and Discussion}

The designed IPS circuit worked properly.

Detail result is as follows:

- Input Transformer:

Primary Input: 220V, $50 \mathrm{~Hz}$.

Secondary Output: 15V, $50 \mathrm{~Hz}$.

- The Charger Circuit:

Input: $15 \mathrm{~V}, 50 \mathrm{~Hz}$

Output: 13.5V DC. (Approximately)

- The Battery: 
Input: $13.5 \mathrm{~V} \mathrm{DC}$.

Output: $12 \mathrm{~V} \mathrm{DC}$.

- Oscillator Circuit:

Input: $12 \mathrm{~V} \mathrm{DC}$.

Output: 11.6V, $312 \mathrm{KHz}$.

- Output Transformer:

Primary Input: 11.6V, $312 \mathrm{KHz}$.

Secondary Output: 220V, $49.6 \mathrm{~Hz}$.

This thesis work was planed in a systematic way. The total activities were performed step by step. At first the whole system was outlined in a block diagram and then circuits of different sections of the block were designed and tested. Finally all the circuits were arranged and connected properly and then tested. Firstly, the charger circuit was designed. A $15 \mathrm{~V}$ AC supply was given to the circuit by a step down transformer and an output of approximately $13.5 \mathrm{~V}$ DC was obtained at the output of voltage regulator LM338K. There was a little voltage drop of about $1.5 \mathrm{~V}$ across the circuit. Then a $12 \mathrm{~V} \mathrm{DC}$ battery was connected to the charge circuit. After that, the oscillator circuit has been designed. To test it a 12V DC supply was applied and proper oscillation was observed by the help of an oscilloscope. An output of approximately $11.6 \mathrm{~V}, 132 \mathrm{KHz}$ was obtained. It was always difficult to obtain a pure AC output.

The output of the oscillator circuit was then applied to the output step up transformer through output transistors and an output of $220 \mathrm{~V}, 49.6 \mathrm{~Hz}$ was acquired. By increasing the number of the output transistors power of the designed circuit can be enhanced.

\section{References}

[1]. http://www.powercombd.com/products/72-instant-power-supply-ips.

[2]. http://en.wikipedia.org/wiki/Transformer.

[3]. http://en.wikipedia.org/wiki/Battery_\%28electricity\%29.

[4]. http://en.wikipedia.org/wiki/Electronic_oscillator.

[5]. Ramakant A. Gayakward, "Op-Amp and Linear Integrated Circuits" 4th edition, Pearson Education. P-279.

[6]. Rezaul Karim Mazumder, "Principles of Electronic Circuit” Banglabazar, Dhaka. P- 469.

[7]. http://www.toolingu.com/definition-460310-34129-power-circuit.html. 